\title{
Ultrastructural Characterization of the Titanium Surface Degree IV in Dental Implant Aluminum Free (Acid Attack)
}

\author{
Igor da Silva Brum ${ }^{(D)}$, Marco Antônio Alencar De Carvalho1 ${ }^{10}$, \\ Paulo Gonçalo Pinto Dos Santos 1 (D), Renan Lana Devita 2 (D), \\ Jorge Luiz da Silva Pires ${ }^{1}$ (1) , Jorge José de Carvalho ${ }^{3^{*}}$ (1)
}

\begin{abstract}
${ }^{1}$ Department of Implantology, Faculty of Dentistry, State University of Rio de Janeiro, Rio de Janeiro, Brazil
${ }^{2}$ Department of Orthodontic, Faculty of Dentistry, State University Barcelona, Barcelona, Spain

${ }^{3}$ Department of Biology, Faculty of Dentistry, State University of Rio de Janeiro, Rio de Janeiro, Brazil

Email: igor_brum1@hotmail.com, odontogermarc@uol.com.br,pgps@domain.com.br, renandevita@hotmail.com,

jorgepires45@gmail.com, *jjcarv@gmail.com
\end{abstract}

How to cite this paper: da Silva Brum, I., De Carvalho, M.A.A., Dos Santos, P.G.P., Devita, R.L., da Silva Pires, J.L. and de Carvalho, J.J. (2020) Ultrastructural Characterization of the Titanium Surface Degree IV in Dental Implant Aluminum Free (Acid Attack). Journal of Biomaterials and Nanobiotechnology, 11, 151-160. https://doi.org/10.4236/jbnb.2020.113009

Received: April 6, 2020

Accepted: May 8, 2020

Published: May 11, 2020

Copyright $\odot 2020$ by author(s) and Scientific Research Publishing Inc. This work is licensed under the Creative Commons Attribution International License (CC BY 4.0).

http://creativecommons.org/licenses/by/4.0/

\section{(c) (i) Open Access}

\begin{abstract}
Following the worldwide trend of developing heavy metal free materials, dental implants aren't out of this tendency. Over the years, a number of techniques to condition the surface of dental implants have been designed and used such as oxide blasting, however the scientific medical community has been concerned about the use of these heavy metals which leads us to investigate and develop new conditioning techniques. The aim of the study was the analysis of the Systhex implant surface in automatic system for the treatment of the surface with acid, where we can identify the surfaces purity level, pore size, deepness and especially the roughness proportionated by the technology of acid conditioning on the titanium surfaces of degree IV dental implants. We conclude that the automatic conditioning of acid attack promoted cleanliness, homogeneity and ideal roughness for the osseointegration process.
\end{abstract}

\section{Keywords}

Dental Implant, Implant Stability Nanotechnology, Surface

\section{Introduction}

It is important to have in my mind that first surfaces didn't present any roughness; they were smooth. Not so long ago the most used technology with better results on roughness was blast of aluminum oxide [1]. Other heavy metal free techniques to promote roughness on dental implants came along as well. For 
example: laser, titanium oxide, anodizing, calcium and magnesium, acid attack-they can be modified with calcium phosphate (often used as nanotechnology) [2].

The first implants designed by Branemark were considered the big ones (for current days) and didn't present any roughness [3] and for this reason the period of osseointegration used to be longer than 8 months. Nowadays this is different, according to the literature we can apply force in the implants a lot earlier [4]. The size and thickness of the implants were modified-they can measure from 4 to $6 \mathrm{~mm}$ (short implant) or from 2.8 to $3.3 \mathrm{~mm}$ (narrow implants) [5] [6].

The two main reasons by which it is possible to achieve this step forward on the development of dental implants are: 1) the progress in the degree of hardness and purity of the titanium used to make the implants [7] — prototypes of smaller sizes can be made with no risk of fracture when being used [8]; 2) the progress of moving from a smooth surface to a controlled rough one, enabling the implants to be placed in a shorter period and with higher chances of durable success [9].

Implants made of titanium and titanium alloys commercially pure are widely accepted and successfully used due to the favorable combination of biocompatible characteristics, corrosion resistance and intrinsic, single propensity to osteointegration [10]. It involves the incorporation of a non-vital component in the living bone, leading to an efficient, reliable and predictable anchoring mechanism. To osseointegrate successfully, an implant must have a firm and immobile connection (without micro-movement at the bone site) between the implant surface and the surrounding bone tissue known as primary stability [11]. The favorable result of the treatment of titanium implants, in vivo, is based on the bio-response of these implants to the osteogenic cells, in other words, osteoblasts during the healing period [12].

The presence of cortical bone influences the primary stability of dental implants. The implant design also presents a statistically significant influence on primary implant stability [13], the progress of the surfaces improves the primary stability statistically and can decrease the reopening period (21 to 42 days) [14].

Brum, I. et al. [15] stated that the success of the implant depends on the response of the cells and tissues in relation to the acceptation of an implant composition, therefore the chemistry of the surface as well as its structural characteristics are related to cellularity. The chemical properties of the surface determine absorption of serum components, regulating the link, the proliferation and differentiation of osteoblastic cells [16].

\section{Objective}

The objective is to analyze the implant surface treated with acid in the Systhex Company in automatic system for the treatment of the surface with acid.

\section{Material and Methods}

\subsection{Sample Receipt}

5 lots containing 20 implants were sent each one, 1 implant was selected from 
each lot (total 5) and sent for analysis. They had the information that they have been produced according to the same industrial criteria of automated acid attack to obtain roughness and homogeneity. Table 1 displays the description of the data provided by the company.

\subsection{Analysis Methodology}

The implant was removed from the packet using stainless steel forceps and placed in the sample holder without any manual contact for analysis in the scanning electron microscope (SEM).

The implant was fixed to the sample holder with double-sided carbon tape. The analysis was performed in high-vacuum using the Field Emission Gun Electron Microscope (FEI QUANTA FEG 250) operated with $30 \mathrm{kV}$.

The recommendations contained in the Technical Standard ABNT NBR were adopted (16,044-2012_dental implants). General requirements for metallic and uncoated end osseous implants.

\section{Results}

Figures 1-7 show the morphologies of the implant surfaces after treatment with acidic solution. In the labels, comments from the different regions analyzed are presented.

\section{Interpretation of Results}

Among the recommendations contained in ABNT NBR 16044-2012 Technical Standard-Dental Implants-General Requirements, item 8 states that “... the product, after surface treatment, must not contain contaminants and must not reduce biocompatibility...”. Item 9.2 of the same Technical Standard there is the "... analysis with scanning electron microscope (SEM), associated with the energy dispersion spectrum analyzer (EDS), with increases of $50 \times, 250 \times, 500 \times$ and 1000x, in three regions: apex, middle third and coronal. The presence of particles or contaminating residues from texturing processing cannot be observed".

The increases used in the present analysis were up to 50,000x. Therefore, the analyses of the surfaces were more critical than those suggested by the ABNT 16,044 - 2012 Standard. Considering that the presence of contaminants was not identified, microanalysis with EDS was not necessary.

Table 1. Description of the analyzed implants. Data provided by the company.

\begin{tabular}{ccccccc}
\hline Reference & Code & Model & Dimension & Lot & Fabrication & Report \\
\hline 877070 & 002611 & AVANTT & $3.5 \times 8.5 \mathrm{~mm}$ & 171,289 & $26 / 12 / 2019$ & $01-2020$ \\
877073 & 002585 & AVANTT & $3.5 \times 13 \mathrm{~mm}$ & $1,712,119$ & $02 / 01 / 2019$ & $02-2020$ \\
8177078 & 002626 & AVANTT & $4.3 \times 13 \mathrm{~mm}$ & 180,190 & $22 / 01 / 2020$ & $03-2020$ \\
877077 & 002620 & AVANTT & $4.3 \times 11.5 \mathrm{~mm}$ & $1,801,112$ & $26 / 01 / 2020$ & $04-2020$ \\
877076 & 002619 & AVANTT & $4.3 \times 10 \mathrm{~mm}$ & $1,801,144$ & $03 / 02 / 2020$ & $05-2020$ \\
\hline
\end{tabular}



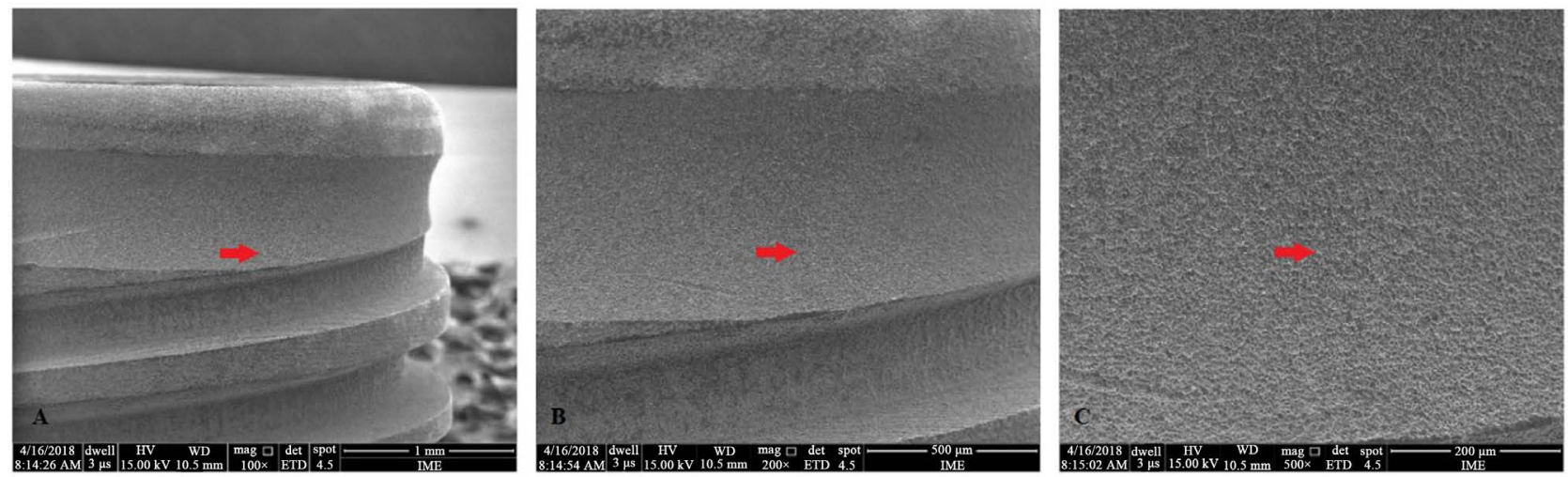

Figure 1. Morphology of the region of the coronal third with detail of the collar. Homogeneous surface and absence of residues from processing. (A-C) Maximum increase of $500 \times$.
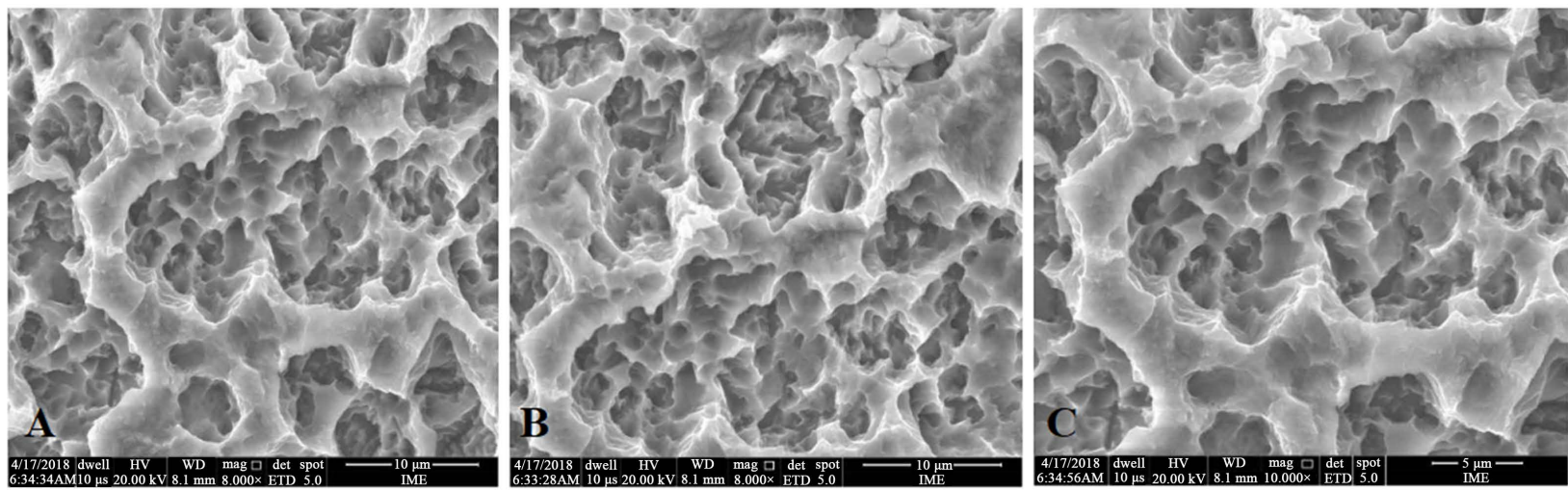

Figure 2. Same region as picture 1 showing details of the necklace. Homogeneous surface and absence of residues from processing. The surface presents roughness with characteristics of acid treatment and adequate for inducing the mechanisms involved in osseointegration. (A-C) Maximum increase of 5000×.
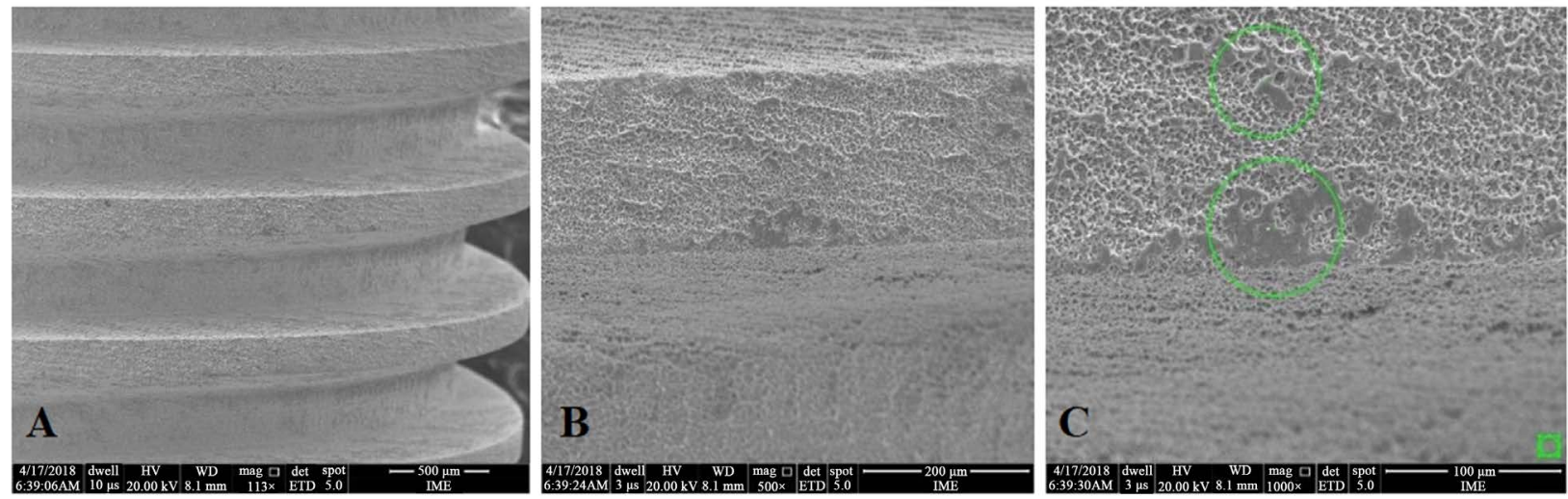

Figure 3. Morphology of the middle third region (A) and (B). Surface presents a smooth region (C). $500 \times$ increase.

\section{Concluding Remarks}

The sample analyzed didn't present any contaminating particles or residues on the surface from texturization processing.

The following observations can be highlighted: 1) The surface regions present homogeneity, exempt from residues from the manufacturing process and 

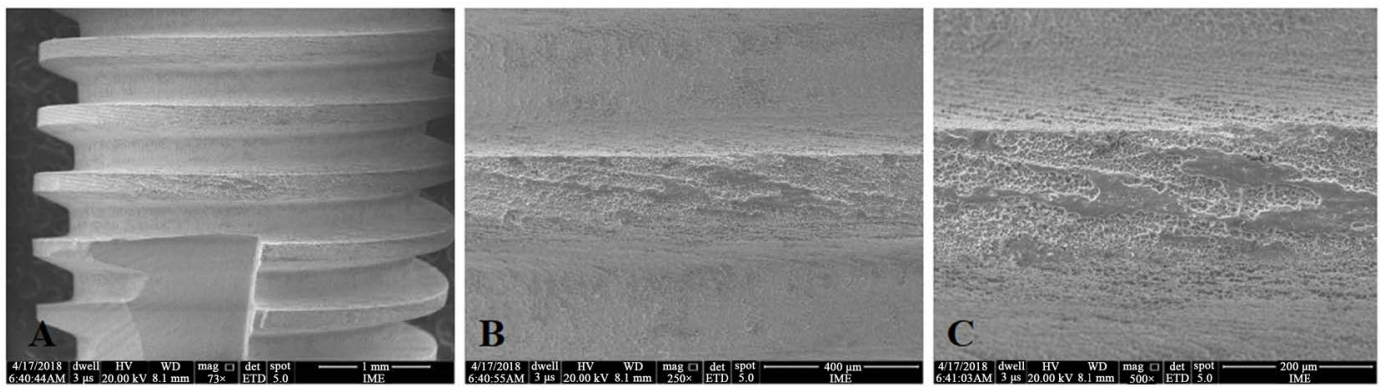

Figure 4. Morphology of the apical third region. (A) Homogeneous surface and absence of residues from processing. (B) The marks on the used cutters have been removed by treating the surface with acid. (C) Maximum increase of $500 \times$.
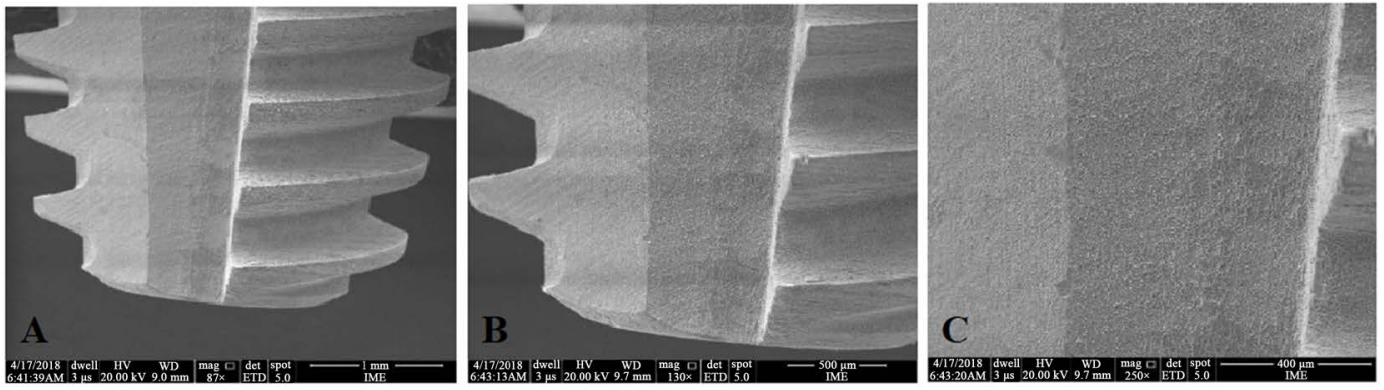

Figure 5. Morphology of the apical third region. (A) and (B) Homogeneous surface and absence of residues from processing. The marks on the used cutters have been removed by treating the surface with acid. The surface presents roughness with characteristics of acid treatment; (C) The surface is adequate to induce the mechanisms involved in osseointegration. Maximum increase of $250 \times$.
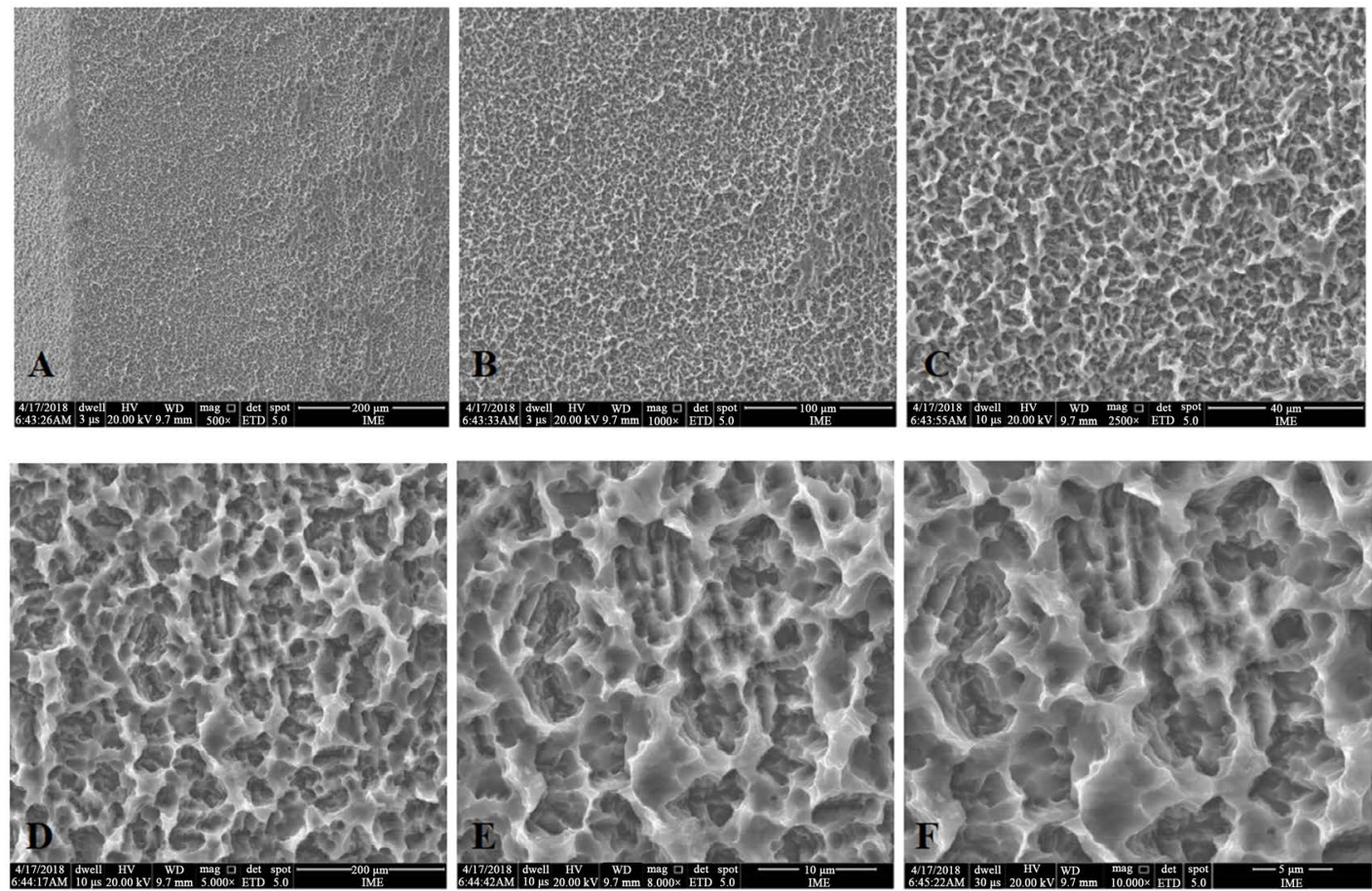

Figure 6. Morphology of the apical third region. Homogeneous surface and absence of residues from processing. (A)-(C) The marks on the used cutters have been removed by treating the surface with acid. The surface presents roughness with characteristics of acid treatment. (D)-(F) The surface is adequate to induce the mechanisms involved in osseointegration. $5000 \times$ maximum increase. 

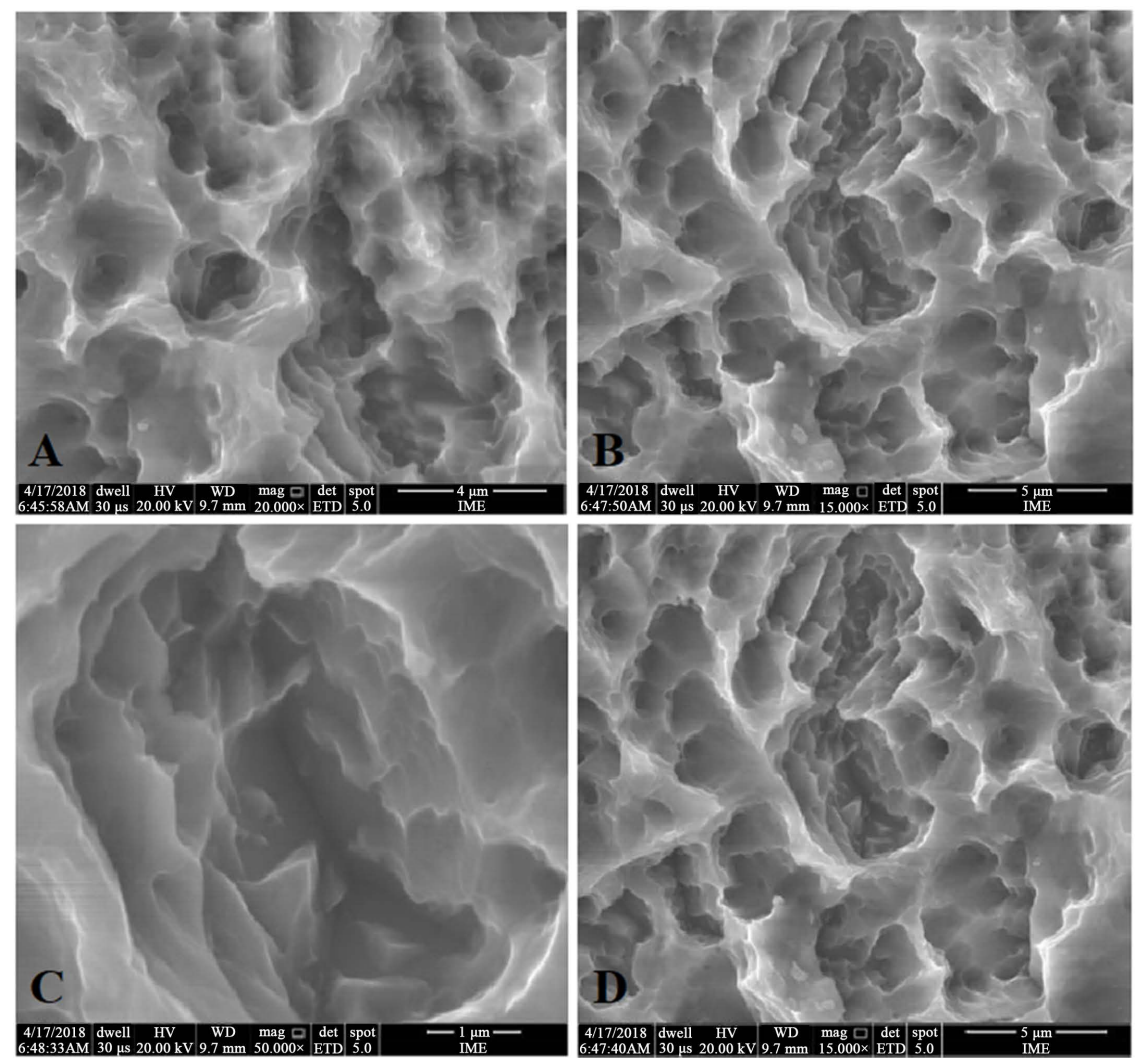

Figure 7. Morphology of the apical third region. Homogeneous surface and absence of residues from processing. The marks on the used cutters have been removed by treating the surface with acid. The surface presents roughness with characteristics of acid treatment. (A)-(D) The surface is adequate to induce the mechanisms involved in osseointegration. Maximum increase of 50,000×.

homogeneous roughness. 2) The surface morphology of the analyzed implant has adequate characteristics for osseointegration.

\section{Discussion}

In this study we could see that treatment with acid conditioning in Systhex implants obtained homogeneity of the roughness and it didn't present any sign of contamination (Figures 1-7). [17] carried out studies using different conditioning surfaces; anodic oxidation (AO), blasting and pickling (SLA) and hydroxyapatite by plasma spray (HA) and revealed that each method obtained good results, however this study revealed that material surface properties can change the cell response that influenced the bioactivities, antibacterial properties and biocompatibility of materials [18].

Boyan, B. et al. [19] stated that the technology of obtaining roughness with aluminum oxide has been used until the present days as an excellent alternative to characterize the roughness of dental implants [20], however the scientific community has been concerned with the use of these metals because there are a few research lines that these contaminations present on the surfaces of the implants may cause future diseases [21]. 
Therefore, new technologies have contributed in this field through different ways to condition the surface [22], which leads to the development of more advanced research, making possible the emergence of different routes to obtain an ideal roughness (Figure 2) in grade IV titanium in dental implants [23].

Nicolas-Silvente, A.I. et al. [24] state that the characteristics of the implant surface affect the osseointegration process. The use of different methods for the surface treatment have been applied to improve topography and its properties [25], on the other hand, state that contamination levels can appear on the implant surfaces, which can modify the surface properties and affect the response of the body.

Nanotopography influences interactions between proteins, cells and implants. These characteristics induce changes in biological, physical and chemical levels, and cause an increase in the adhesion of osteogenic cells and the promoting the osseointegration [26]. It has been postulated that micro and nanosurfaces can influence osteoblastic activity and, therefore, the osteoconduction process [27]. For that matter, some authors showed an increase in the rate bone contact with implants (BIC) with a greater number of cells in a period of $4-10$ weeks in a surface presenting greater roughness. The current trend is to apply a treatment on the surface that creates the appropriate roughness to promote cell adhesion and bone neoformation [28].

Another important topic to be mentioned is the effects of new metal-free surfaces on cell adhesion after using biomaterials [29]. The authors suggest that the presence of the biomaterial may facilitate stabilization and support the invasion of osteoprogenitor cells and access to the implant surface. However, [30] described the effects of the hydrophilic surfaces of dental implants on defects grafted with bone substitutes are not fully mapped. Also, the results suggest that the association between hydrophilic porous surfaces and biomaterials have an optimizing effect on the osseointegration process [31].

It is known that dental implant surface treatments present a great impact on its osseointegration rate. [32] carried out a study comparing the biocompatibility between bone contact with implants (BIC) and different surface treatments. This study proved that surface properties of materials can influence bioactivities, antibacterial properties and biocompatibilities of materials in contact with dental implants [33] [34].

\section{Conclusions}

Based on this study, it is possible to conclude that, through ultrastructural analyses, the conditioning with acid attack in degree IV titanium surfaces from Systhex ${ }^{\oplus}$ obtained the following conditions:

- The surface of the implants does not have contaminants from the texturization process.

- The roughness found on the implant body surface is homogeneous. This characteristic eases the osseointegration process since there is an increasing cell adhesion. 
- The surface morphology of the analyzed implant presents suitable characteristics for satisfactory osseointegration in 42 days, provided that there is a proper torque $(45 \mathrm{~N} \cdot \mathrm{cm})$ and good bone quality.

\section{Acknowledgements}

The authors thank Carlos Nelson Elias, Doctor of Materials Science for accomplished the figures in the scanning electron microscope.

\section{Conflicts of Interest}

The authors declare no conflicts of interest regarding the publication of this paper.

\section{References}

[1] Yurttutan, M.E. and Keskin, A. (2018) Evaluation of the Effects of Different Sand Particles That Used in Dental Implant Roughened for Osseointegration. BMC Oral Health, 18, 47. https://doi.org/10.1186/s12903-018-0509-3

[2] Wennerberg, A. and Albrektsson, T. (2009) Effects of Titanium Surface Topography on Bone Integration: A Systematic Review. Clinical Oral Implants Research, 20, 172-184. https://doi.org/10.1111/j.1600-0501.2009.01775.x

[3] El Chaar, E., Zhang, L., Zhou, Y., et al. (2019) Osseointegration of Superhydrophilic Implants Placed in Defect Grafted Bones. The International Journal of Oral \& Maxillofacial Implants, 34, 443-450. https://doi.org/10.11607/jomi.7172

[4] Jensen, O.T. (2015) Dental Extraction, Immediate Placement of Dental Implants, and Immediate Function. Oral and Maxillofacial Surgery Clinics of North America, 27, 273-282. https://doi.org/10.1016/j.coms.2015.01.008

[5] Mehta, H. and Shah, S. (2015) Management of Buccal Gap and Resorption of Buccal Plate in Immediate Implant Placement: A Clinical Case Report. Journal of International Oral Health, 7, 72-77.

[6] Ferreira Mattos, C., Alencar De Carvalho, M.A., De Carval-ho, J.J., Pinto Dos Santos, P.G., Da Silva Pires, J.L. and Da Silva Brum, I. (2020) Use of Extra-Narrow-Diameter Implants in Reduced Alveolar Ridge: A Case Report. Journal of Biomaterials and Nanobiotechnology, 11, 101-109. https://doi.org/10.4236/jbnb.2020.112007

[7] Gasik, M. (2017) Understanding Biomaterial-Tissue Interface Quality: Combined in Vitro Evaluation. Science and Technology of Advanced Materials, 18, 550-562. https://doi.org/10.1080/14686996.2017.1348872

[8] Hu, X.N. (2014) Conformation Change of Bovine Serum Albumin Induced by Bioactive Titanium Metals and Its Effects on Cell Behaviors. Journal of Biomedical Materials Research Part A, 102, 1053-1062. https://doi.org/10.1002/jbm.a.34768

[9] Akbarian, S., Sojoodi, J., Monnavari, F., Heidari, H., Khosravian, P., Javar, H.A., Assadi, A., Rasouli, R., Saffari, M. and As Shandiz, S. (2017) Nano Conjugated PLGA-Chlorambucil: Synthesis in Vitro Anti Non-Hodgkin's Lymphoma Cellular Assay. Letters in Drug Design \& Discovery, 14, 827-836. https://doi.org/10.2174/1570180814666161130113446

[10] Henningsen, A., Smeets, R., Hartjen, P., Heinrich, O., Heuberger, R., Heiland, M., et al. (2017) Photofunctionalization and Non-Thermal Plasma Activation of Titanium Surfaces. Clinical Oral Investigations, 22, 1045-1054. 
https://doi.org/10.1007/s00784-017-2186-Z

[11] Osborn, J.F., Willich, P. and Meenen, N. (1990) The Release of Titanium into Human Bone from a Titanium Implant Coated with Plasma-Sprayed Titanium. In: Heimke, G., Soltesz, V. and Lee, A.J.C., Eds., Clinical Implant Materials. Advances in Biomaterials, Vol. 1, Elsevier, Amsterdam, 75-80.

[12] Das, S., Dholam, K., Gurav, S., Bendale, K., Ingle, A., Mohanty, B., et al. (2019) Accentuated Osseointegration in Osteogenicnanofbrous Coated Titanium Implants. Scientific Reports, 9, Article No. 17638. https://doi.org/10.1038/s41598-019-53884-x

[13] Chávarri-Prado, D., Brizuela-Velasco, A., Diéguez-Pereira, M., Pérez-Pevida, E., Jiménez-Garrudo, A., Viteri-Agustín, I., Estrada-Martínez, A. and Montalbán-Vadillo, O. (2020) Influence of Cortical Bone and Implant Design in the Primary Stability of Dental Implants Measured by Two Different Devices of Resonance Frequency Analysis: An in Vitro Study. Journal of Clinical and Experimental Dentistry, 12, e242-e248. https://doi.org/10.4317/jced.56014

[14] Sugiura, T., Yamamoto, K., Horita, S., Murakami, K., Tsutsumi, S. and Kirita, T. (2016) The Effects of Bone Density and Crestal Cortical Bone Thickness on Micromotion and Peri-Implant Bone Strain Distribution in an Immediately Loaded Implant: A Nonlinear Finite Element Analysis. Journal of Periodontal \& Implant Science, 46, 152-165. https://doi.org/10.5051/jpis.2016.46.3.152

[15] da Silva Brum, I., José deCarvalho, J., daSilvaPires, J.L., deCarvalho, M.A.A., dosSantos, L.B.F. and Elias, C.N. (2019) Nanosized Hydroxyapatite and $\beta$-Tricalcium Phosphate Composite: Physico-Chemical, Cytotoxicity, Morphological Properties and in Vivo Trial. Scientific Reports, 9, Article ID: 19602. https://doi.org/10.1038/s41598-019-56124-4

[16] MacDonald, D.E., Markovic, B., Allen, M., Somasundaran, P. and Boskey, A.L. (1998) Surface Analysis of Human Plasma Fibronectin Adsorbed to Commercially Pure Titanium Materials. Journal of Biomedical Materials Research, 41, 120-130. https://doi.org/10.1002/(SICI)1097-4636(199807)41:1<120::AID-JBM15>3.0.CO;2-R

[17] Rasouli, R., Barhoum, A. and Uludag, H. (2018) A Review of Nanostructured Surfaces and Materials for Dental Implants: Surface Coating, Patterning and Functionalization for Improved Performance. Biomaterials Science, 6, 1312-1338. https://doi.org/10.1039/C8BM00021B

[18] Tabibi, S., Kegel, A., Lai, W.K., Bruce, I.C. and Dillier, N. (2019) Measuring Temporal Response Properties of Auditory Nerve Fibers in Cochlear Implant Recipients. Hearing Research, 380, 187-196. https://doi.org/10.1016/j.heares.2019.07.004

[19] Boyan, B., Dean, D.D., Lohmann, C.H., Cochran, D.L., Sylvia, V.L. and Schwartz, D.K. (2001) The Titanium-Bone Cell Interface in Vitro: The Role of the Surface in Promoting Osteointegration. In: Brunette, D.M., Tengvall, P., Textor, M. and Thomsen, P., Eds., Titanium in Medicine: Material Science Surface Science Engineering Biological Responses and Medical Applications, Springer, Berlin, 561-585.

[20] Anselme, K., Bigerelle, M., Noel, B., et al. (2000) Qualitative and Quantitative Study of Human Osteoblast Adhesion on Materials with Various Surface Roughnesses. Journal of Biomedical Materials Research, 49, 155-166. https://doi.org/10.1002/(SICI)1097-4636(200002)49:2<155::AID-JBM2>3.0.CO;2-J

[21] Brunette, D.M. (2001) Principles of All Behavior on Titanium Surfaces and Their Application to Implanted Devices. In: Brunette, D.M., Tengvall, P., Textor, M. and Thomsen, P., Eds., Titanium in Medicine, Springer, Berlin, 485-512. https://doi.org/10.1007/978-3-642-56486-4_15

[22] Lang, N.P., Salvi, G.E., Huynh-Ba, G., Ivanovki, S., Donos, N. and Bosshardt, D.D. (2011) Early Osseointegration to Hydrophilic and Hydrophobic Implant Surfaces in 
Humans. Clinical Oral Implants Research, 22, 349-356.

https://doi.org/10.1111/j.1600-0501.2011.02172.x

[23] Minamikawa, H., Att, W., Ikeda, T., Makoto, H. and Ogawa, T. (2016) Long-Term Progressive Degradation of the Biological Capability of Titanium. Materials, 9, 102. https://doi.org/10.3390/ma9020102

[24] Nicolas-Silvente, A.I., Velasco-Ortega, E., Ortiz-Garcia, I., Monsalve-Guil, L., Gil, J. and Jimenez-Guerra, A. (2020) Influence of the Titanium Implant Surface Treatment on the Surface Roughness and Chemical Composition. Materials (Basel), 13, pii: E314. https://doi.org/10.3390/ma13020314

[25] Saffarpour, A., Nozari, A., Fekrazad, R., Saffarpour, A., Heibati, M.N. and Iranparvar, K. (2018) Microstructural Evaluation of Contaminated Implant Surface Treated by Laser, Photodynamic Therapy, and Chlorhexidine 2 Percent. The International Journal of Oral \& Maxillofacial Implants, 33, 1019-1026.

https://doi.org/10.11607/jomi.6325

[26] Jeevanandam, J., Barhoum, A., Chan, Y.S., Dufresne, A. and Danquah, M.K. (2018) Review on Nanoparticles and Nanostructured Materials: History, Sources, Toxicity and Regulations. Beilstein Journal of Nanotechnology, 9, 1050-1074.

https://doi.org/10.3762/bjnano.9.98

[27] Sudha, P.N., Sangeetha, K., Vijayalakshmi, K. and Barhoum, A. (2018) Nanomaterials History, Classification, Unique Properties, Production and Market. In: Makhlouf, A.S.H. and Barhoum, A., Eds., Emerging Applications of Nanoparticles and Architecture Nanostructures, Elsevier, Cambridge, 341-384. https://doi.org/10.1016/B978-0-323-51254-1.00012-9

[28] Petruželka, J., Dluhoš, L., Hrušák D. and Sochová, J. (2006) Nanostructured Titanium-Application in Dental Implants.

[29] Webster, T.J., Siegel, R.W. and Bizios, R. (1999) Design and Evaluation of Nanophase Alumina for Orthopaedic/Dental Applications. Nanostructured Materials, 12, 983-986. https://doi.org/10.1016/S0965-9773(99)00283-4

[30] Trento, G., Carvalho, P.H., Reis, E.N.R., Spin-Neto, R., Bassi, A.P.F. and Pereira-Filho, V.A. (2020) Bone Formation around Two Titanium Implant Surfaces Placed in Bone Defects with and without a Bone Substitute Material: A Histological, Histomorphometric, and Micro-Computed Tomography Evaluation. Clinical Implant Dentistry and Related Research, 22, 177-185.

https://doi.org/10.1111/cid.12880

[31] Pinotti, F.E., Oliveira, G.J.P.L., Aroni, M.A.T., Marcantonio, R.A.C. and Marcantonio, E. (2018) Analysis of Osseointegration of Implants with Hydrophilic Surface in Grafted Areas: A Preclinical Study. Clinical Oral Implants Research, 29, 963-972. https://doi.org/10.1111/clr.13361

[32] Yamamoto, H., Shibata, Y. and Miyazaki, T. (2005) Anode Glow Discharge Plasma Treatment of Titanium Plates Facilitates Adsorption of Extracellular Matrix Proteins to the Plates. Journal of Dental Research, 84, 668-671. https://doi.org/10.1177/154405910508400717

[33] Hoornaert, A., Vidal, L., Besnier, R., Morlock, J.F., Louarn, G. and Layrolle, P. (2020) Biocompatibility and Osseointegration of Nanostructured Titanium Dental Implants in Minipigs. Clinical Oral Implants Research. https://doi.org/10.1111/clr.13589

[34] Browne, M. and Gregson, P.J.R. (1996) Characterization of Titanium Alloy Implant Surfaces with Improved Dissolution Resistance. Journal of Materials Science: Materials in Medicine, 7, 323-329. https://doi.org/10.1007/BF00154543 